\title{
THỰC TRANG RĂNG SỮA DÍNH, RĂNG SỮA SINH ĐÔI CỦA TRẺ 3-5 TUỔI VÀ Tİ̀NH TRANG KHỚP CẮN CỦA TRẺ Có RĂNG BẤT THƯỜNG NÀY TẠI MộT SỐ TRƯờNG MẪU GIÁO Ở HÀ NộI, VIỆT NAM, NĂM 2017
}

\author{
Lương Minh Hằng1, Lâm Thị Sen², Võ Trương Như Ngọc¹,
} Lê Thị Thùy Linh ${ }^{1}$, Nguyễn Hà Thu ${ }^{1}$, Vũ Thị Dịu ${ }^{1}$

\section{TÓM TẮT}

Nghiên cứu mô tả cắt ngang trên 1453 trẻ nhằm mô tả thực trạng răng sữa dính, răng sữa sinh đôi và đánh giá tình trang khớp cắn của các trẻ có răng bất thường này ở một số trường mẫu giáo tại Hà Nội, Việt Nam năm 2017. Kết quả: nghiên cứu cho thấy: Tỷ lề răng dính, răng sinh đôi là 2,4\%, trong đó răng dính chiếm $92,1 \%$ và răng sinh đôi chiếm $7,9 \%$; bất thường răng dính, răng sinh đôi đều xảy ra ở vùng răng trước và $89,5 \%$ xảy ra ở hàm dưới; $6,7 \%$ răng dính gặp ở hai bên. Tương quan răng hàm sữa thứ hai theo bình diện giới hạn phía xa của trẻ có răng dính, răng sinh đồi: kiểu bậc gần chiếm 45,7\%, kiểu mặt phẳng chiếm $37,2 \%$, kiểu bậc xa 17,1\%. 100\% cung răng của trẻ có răng sinh đôi không có khe hở và $90,6 \%$ trẻ có răng dính có cung răng có khe hở. Kết luận: răng dính, răng sinh đôi là bất thường răng hiếm gặp, răng dính hay gặp hơn răng sinh đôi. Việc xuất hiện răng dính, răng sinh đôi trên cung hàm có những ảnh hưởng nhất định đến khớp cắn của trẻ sữa

Tư khóa: răng dính, răng sinh đôi, khớp cắn, răng

\section{SUMMARY}

STATUS OF PRIMARY DOUBLE TOOTH IN CHILDREN IN THE AGE OF 3 TO 5 AND THEIR OCCLUSIONS AT SOME KINDERGARTENS IN HA NOI, VIET NAM, 2017

A cross-sectional descriptive study at 1453 children to describe status of primary double tooth (PDT) at some kindergartens in $\mathrm{Ha}$ Noi in 2017, and to evaluate the occlusion in children having these abnormal teeth. Results: The prevalence of PDT was 2,4\% with $92,1 \%$ fused teeth and $7,9 \%$ germinated teeth. All of PDTs were anterior teeth, $85,9 \%$ of them were located in mandibular arch, only $6,7 \%$ of the cases exhibited a bilateral distributions, most of the children with PDTs had a unilateral distribution (93,3\%). About primary molar relationship (terminal plane): mesial step, distal step and flush terminal plane accounted for $45,7 \%, 17,1 \%$, and $37,2 \%$ respectively. $100 \%$ children with geminated teeth had no physiologic space between primary teeth, and in children having fused teeth, this percentage was $90,6 \%$.

1 Viện Đào tạo Răng Hàm Mặt, Đại học Y Hà Nội

${ }^{2}$ Đại học Y Dước, Đại học Quốc gia Hà Nội

Chịu trách nhiệm chính: Lương Minh Hằng

Email: minhhang@hmu.edu.vn

Ngày nhận bài: 10.5.2021

Ngày phản biên khoa học: 25.6.2021

Ngày duyệt bài: 5.7.2021
Conclusions: PDTs were a rarely morphologic abnormality. Most of them were located in anterior area of mandibular arch and exhibited a unilateral distribution. The prevalence of fusion was higher than germination. The presence of PDTs can effect to children's occlusion.

Keywords: fused teeth, geminated teeth, occlusion, primary teeth,...

\section{I. ĐẶT VẤN ĐỀ}

Răng dính và răng sinh đôi là bất thường về hình dạng đã được nghiên cứu nhiều trên thễ giới ở trên cả hai hệ răng sữa và răng vĩnh viễn. Ớ hầu hết các nghiên cứu đều cho thấy tỷ lệ răng dính, răng sinh đôi ở bộ răng sữa cao hơn đáng kể so với ở bộ răng vĩnh viễn. Theo nghiên cứu năm 2014 thì tỷ lệ răng dính, răng sinh đôi là $0,42 \%$ ở bộ răng vĩnh viển [1], trong khi tỷ lệ răng dính, răng sinh đôi ở hàm răng sữa khoảng 0,6\%- 3,7\% [2], [3], [4], [5].

Răng dính và răng sinh đôi làm tăng tỷ lệ sâu răng và bệnh lý nha chu do vị trí rãnh dọc thân răng khó làm sạch ở những răng này [5]; gây ra những vấn đề về thẩm mỹ, khớp cắn do răng có kích thước, hình dạng bất thường ở vùng răng phía trước, tạo những khe thưa hoặc làm chen chúc các răng lân cận [6], [7], [8]. Đặc biệt răng dính, răng sinh đôi ở bộ răng sữa còn có thể gây ảnh hưởng đến mầm răng thay thế ở bộ răng vĩnh viễn với tỉ lệ cao: $41,3 \%$ theo kết quả nghiên cứu năm 2014 [2], 50\% [9], và lên tới $57,1 \%$ theo kết quả nghiên cứu năm 2013 [3]. Các bất thường hay gặp là thiếu răng, thừa răng, răng dính, răng sinh đôi lặp lại ở răng vĩnh viển tương ứng, gây những vấn đề không nhỏ cho bộ răng vĩnh viển của trẻ sau này [3], [6].

Vì thế việc phát hiên, thăm khám để có kế hoạch theo dõi và phương án điều trị phù hợp những trẻ có răng dính và răng sinh đôi ở giai đoạn bộ răng sữa là rất cần thiết và có ý nghĩa.

ở việt Nam, nghiên cứu về vấn đề răng dính, răng sinh đôi còn nhiều hạn chế, vì thế chúng tối tiến hành nghiên cứu này với mục tiêu: Mô tả thực trạng răng sữa dính, răng sữa sinh đôivà tình trạng khớp cắn các trẻ này tại một số trường mẩu giáo ở Hà Nội, Việt Nam năm 2017.

II. ĐỐı TƯợNG VÀ PHƯƠNG PHÁP NGHIÊN CỨU 
1. Đối tượng nghiên cứu. Trẻ từ ba đến năm tuổi (sinh từ 1/1/2011 đến 31/12/2013) đang học tại ba trường mầm non được chọn tại Hà Nội: Trường Mầm non Việt Triều, Trường Mẫu giáo số 3, Trường Mầm non Tuổi Hoa.

Tiêu chuẩn lựa chọn: Trẻ còn đầy đủ các răng sữa, chưa mọc răng hàm lớn vĩnh viễn thứ nhất, các răng hàm sữa thứ nhất và thứ hai không có tổn thương sâu răng mặt bên, có tình trạng sức khỏe bình thường, hợp tác và được cha me đồng ý cho tham gia nghiên cứu.

Tiều chuẩn loại trừ: Trẻ không đủ tiêu chuẩn lựa chọn trên, trẻ có dị tật bẩm sinh vùng hàm mặt.

\section{Phương pháp}

2.1 Thởi gian và địa điểm nghiên cứu:

Địa điểm nghiên cứu: Trường Mấu giáo Việt Triều Hữu Nghị; trường Mẫu giáo số 3; trường Mầm non Tuổi Hoa, Thanh Xuân, Hà Nội.

Thời gian nghiên cứu: Từ tháng 10/2016 đến tháng 6/2017.

2.2. Thiêt kế nghiên cứu: Nghiên cứu mô tả cắt ngang.

2.3. Phương pháp chọn mẫu: chọn mẫu thuận tiện

2.4. Xử lý và phân tích số liệu. Sử dụng phần mềm SPSS 16.0 và thuật toán thống kê

3. Đạo đức nghiển cứu: - Tuân thủ các nguyên tắc vệ sinh, vô trùng khi khám.

- Đối tượng nghiên cứu có sự đồng ý của bố mẹ.

- Mọi thông tin do đối tượng cung cấp đều được giữ bí mật.

- Đề tài nghiên cứu chỉ nhằm mục đích phục vụ nghiên cứu khoa học, không nhằm bất cứ mục đích nào khác.

\section{KẾT QUẢ NGHIÊN CỨU}

1. Thực trạng răng dính, răng sinh đôi của trẻ

Bảng 1: Thực trang răng dính, răng sinh đôi của trẻ 3-5 tuổi ở một số trường mấu giáo tại Hà Nội, năm 2017

\begin{tabular}{|c|c|c|c|}
\hline Tống số răng dính, & $\mathbf{N}$ & $\mathbf{\%}$ & $\mathbf{p}$ \\
\cline { 2 - 3 } răng sinh đôi & 35 & 2,4 & \\
\hline Nam & 21 & 60 & \\
\hline Nữ & 14 & 40 & \\
\hline Răng dính & 32 & 91,4 & \\
\hline Răng sinh đôi & 3 & 8,6 & \\
\hline Một bên & 33 & 94,3 & \multirow{2}{*}{$\mathrm{p}<0,05$} \\
\hline Hai bên & 2 & 5,7 & \\
\hline Hàm trên & 4 & 11,4 & \multirow{2}{*}{$\mathrm{p}<0,05$} \\
\hline Hàm dưới & 31 & 88,6 & \\
\hline Vùng răng trước & 35 & 100 & \\
\hline Vùng răng sau & 0 & 0 & \\
\hline
\end{tabular}

Nhận xét: Trong 1453 trẻ có 35 trẻ tham gia nghiên cứu có răng dính, răng sinh đôi (chiếm 2,4\%), 1418 trẻ còn lại không có răng dính, răng sinh đôi (chiếm 97,6\%).

Trong tổng số 35 trẻ có răng dính, răng sinh đôi: Có 21 trẻ nam (chiếm 60\%) và 14 trẻ nữ (chiếm 40\%). Sự khác biệt này không có ý nghĩa thống kê với $p<0,05$ (kiểm định khi bình phương).

Có 32 trường hợp răng dính và 3 trường hợp răng sinh đôi tương ứng $91,4 \%$ và $8,6 \%$.

Có 33 trường hợp răng dính, răng sinh đôi ở một bên (chiếm 94,3\%), 2 trường hợp ở 2 bên (chiếm 5,7\%).

Về sự phân bố theo vùng răng, có 31 trường hợp răng bất thường ở hàm dưới và 4 trường hợp ở hàm trên tương ứng với $88,6 \%$ và $11,4 \%$.

$100 \%$ răng dính, răng sinh đôi nằm ở vùng răng trước.

2. Đặc điểm khớp cắn của trẻ có răng dính, răng sinh đôi

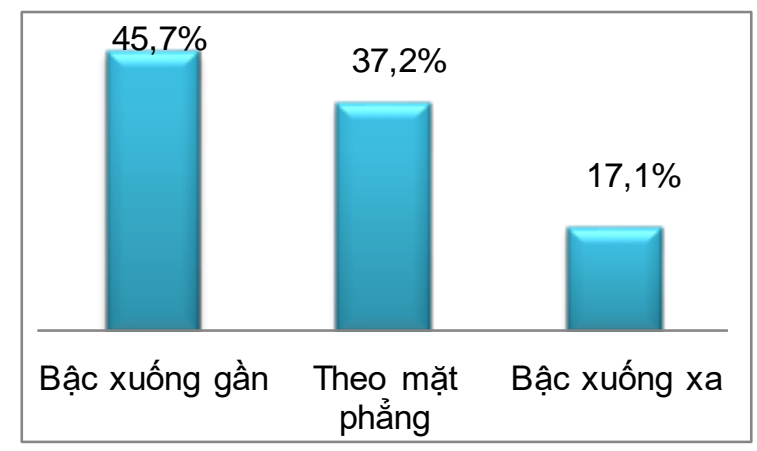

Biểu đồ 1. Tỷ lệ tương quan răng hàm sữa thứ hai theo binh diện phía xa

Nhận xét: Nghiên cứu tiến hành lấy mẫu hàm của trẻ có bất thường răng để xác định tương quan răng hàm sữa thứ hai theo bình diện giới hạn phía xa. Đối với các trẻ có tương quan ở hai bền khác nhau, chúng tôi ưu tiên lấy tương quan ở bên có răng bất thường. Kết quả thu được là: trong số 35 trẻ có bất thường răng, có 16 trẻ có tương quan bình diện phía xa răng hàm sữa thứ hai theo kiểu bậc xuống gần (chiếm $45,7 \%)$, tương quan theo mặt phẳng chiếm tỷ lệ ít hơn với 13 trẻ (chiếm 37,2\%), tương quan theo bậc xuống xa chiếm tỷ lệ ít nhất với 6 trẻ (chiếm 17,1\%).

Bảng 2: Tỷ lê cung răng có khe hở và không có khe hớ

\begin{tabular}{|c|c|c|c|c|}
\hline $\begin{array}{c}\text { Khe hở cung } \\
\text { răng }\end{array}$ & \multicolumn{2}{|c|}{ Răng dính } & \multicolumn{2}{|c|}{ Răng sinh đôi } \\
\cline { 2 - 5 } & $\mathbf{n}$ & $\mathbf{\%}$ & $\mathbf{n}$ & $\mathbf{\%}$ \\
\hline Có khe hở & 29 & 90,6 & 0 & 0 \\
\hline Không có khe hở & 3 & 9,4 & 3 & 100 \\
\hline Tổng & 32 & 100 & 3 & 100 \\
\hline
\end{tabular}


Nhận xét. Trong 32 trẻ có răng dính, có 29 trẻ có cung răng thuộc loại có khe hở (chiếm 90,6\%), 3 trẻ có cung răng thuộc loại không có khe hở (chiếm 9,4\%). Cả 3 trường hợp có răng sinh đôi đều có cung răng thuộc loại khồng có khe hở.

\section{BÀN LUẬN}

1. Thực trạng răng dính, răng sinh đôi của trẻ. Tỷ lệ trẻ có răng dính, răng sinh đôi là $2,4 \%$. Tỷ lệ này cao hơn nhiều so với các nghiên cứu khác trên thế giới như nghiên cứu năm 2014 tại Thổ Nhĩ Kỳ là 0,63\% [2], hay 0,98\% trong một nghiên cứu khác ở Brazil năm 2013 [3].

Có sự khác biệt trong kết quả nghiên cứu này của chúng tôi so với các nghiên cứu khác trên thế giới có thể do cỡ mẫu của chúng tôi thấp hơn so với những nghiên cứu khác trên thế giới, và đối tượng nghiên cứu của chúng tôi thu hẹp trong độ tuổi 3 - 5 tuổi, trong khi một số nghiên cứu khác lựa chọn độ tuổi của trẻ rộng hơn như độ tuổi 5 - 12 [2], hay độ tuổi 2 - 5 tuổi [2]. Hoặc cũng có thể sự khác biệt tỷ lệ này là do đặc điểm riêng của đối tượng ở từng khu vực (ví dụ như: chủng tộc, các yểu tố tác động của môi trường....).

Trong số 35 trẻ có răng bất thường có 21 trẻ nam (chiếm 60\%) và 14 trẻ nữ (chiếm 40\%). Sự khác biệt này không có ý nghĩa thống kê với $\mathrm{p}<0,05$ (kiểm đinh khi bình phương). Cũng như kết quả nghiên cứu của chúng tôi, đa số các nghiên cứu khác cũng cho rằng không có sự khác biệt tỷ lệ răng dính giữa nam và nữ với tỷ lệ trẻ nam và trẻ nữ có răng dính, răng sinh đôi lẩn lượt là $0,31 \%$ và $0,47 \%$; hay trong một nghiên cứu khác thì tỷ lệ trẻ nam là $57,0 \%$ và tỷ lệ trẻ nữ là 43,0\%.

Có 32 trường hợp răng dính và 3 trường hợp răng sinh đôi tương ứng $91,4 \%$ và $8,6 \%$. Kết quả này tương tự với các nghiên cứu khác như một nghiên cứu năm 2013 với $82,4 \%$ răng dính và $17,6 \%$ răng sinh đôi trong tổng số 17 trẻ có bất thường răng [2]; một nghiên cứu khác tiến hành trên 49 trường hợp bất thường răng dính, răng sinh đôi cho thấy $93,9 \%$ là răng dính và chỉ có $6,1 \%$ là răng sinh đôi.

Về phân bố theo vị trí có 33 trường hợp răng dính, răng sinh đôi ở một bên (chiếm 94,3\%), 2 trường hợp ở 2 bên (chiếm 5,7\%). Kết quả này phù hợp với các nghiên cứu khác. Theo kết quả một nghiên cứu năm 2014 có 13 trường hợp xảy ra ở một bên $(92,9 \%)$, và chỉ có 1 trường hợp xảy ra ở cả hai bên $(7,1 \%)$ trong 14 trẻ có răng dính, răng sinh đôi [2]. Cũng tương tự, kết quả của một nghiên cứu cùng năm cho thấy răng dính, răng sinh đôi một bên chiếm $81,8 \%$ so với $18,2 \%$ của răng dính, răng sinh đôi hai bên.

Về sự phân bố theo vùng răng, trong 35 trẻ có răng dính, răng sinh đôi thì 31 trường hợp răng bất thường ở hàm dưới và 4 trường hợp ở hàm trên tương ứng với $88,6 \%$ và $11,4 \%$. $100 \%$ răng dính, răng sinh đôi nằm ở vùng răng trước. Các nghiên cứu khác cũng chỉ ra rằng các trường hợp răng dính, răng sinh đôi ở HD là chủ yễu và hiếm gặp ở vùng răng sau như một nghiên cứu trên 14 trẻ có răng dính, răng sinh đôi thì có 13 trường hợp xảy ra ở một bên $(92,9 \%)$, và chỉ có 1 trường hợp xảy ra ở cả hai bên $(7,1 \%)$ [2]. Cũng tương tự, kết quả của một nghiên cứu khác cho thây răng dính, răng sinh đôi một bên chiếm $81,8 \%$ so với $18,2 \%$ của răng dính, răng sinh đôi hai bên và có 10 răng ở hàm dưới $(90,9 \%)$, và 1 răng ở hàm trên $(9,1 \%)$.

2. Đặc điểm khớp cắn của trẻ có răng dính, răng sinh đôi. Đánh giá khớp cắn của trẻ có răng dính, răng sinh đôi cho thấy tương quan bình diện phía xa răng hàm sữa thứ hai theo kiểu bậc xuống gần chiếm tỷ lệ cao nhất, tương quan theo mặt phẳng và tương quan theo bậc xuống xa chiểm tỷ lệ ít hơn. Theo báo cáo của một nghiên cứu trên 519 trẻ 3-5 tuổi kiểu tương quan theo mặt phẳng chiếm ưu thế với $65,1 \%$, trong khi kiểu bậc xuống gần và bậc xuống xa chỉ chiếm lần lượt $18,3 \%$ và 16,5\%. Cũng theo nghiên cứu khác trên 808 trẻ dưới 6 tuổi thấy tương quan răng hàm sữa thứ hai theo bình diện giới hạn phía xa kiểu theo mặt phẳng cũng chiếm phần lớn với tỷ lệ $67,7 \%$ ở bên phải và $68,1 \%$ ở bên trái. Như vậy khớp cắn có răng dính, răng sinh đôi có sự giảm tỷ lệ kiểu tương quan mă̆t phẳng và tăng tỷ lệ kiểu bước gân lên đáng kể. Điều này có thể được giải thích là khi có bất thường răng dính, răng sinh đôi thì chiều dài cung răng thường ngắn hơn bình thường mà bất thường răng dính, răng sinh đôi lại chủ yếu xảy ra ở hàm dưới nên ở các trường hợp có bất thường răng dính, răng sinh đôi cung răng hàm dưới thường ngắn hơn cung răng hàm trên và các răng hàm sữa thứ hai hàm dưới có xu hướng nằm ở phía trước hơn so với răng hàm sữa thứ hai hàm trên.

Trong 32 trẻ có răng dính, $90,6 \%$ số trẻ có cung răng thuộc loại có khe hở. Theo nghiên cứu trên bộ răng người Việt về khe hở giữa các răng ở cung răng sữa trẻ 3 tuổi thấy có đến $99,98 \%$ cung răng có khe hở (có ít nhất một khe hở) và chỉ có $0,02 \%$ cung răng không có bất kỳ khe hở nào. Điều này có vẻ như không hợp lý vì khi các răng dính nhau thì sẽ xảy ra hiện tượng thừa 
khoảng trên cung hàm do các răng dính nhau cần ít khoảng trống trên cung hàm hơn so với các răng bình thường, do đó ngoài các khoảng hở sinh lý trên cung răng sữa như khe linh trưởng, khe hở giữa các răng cửa sữa thì trên cung răng có bất thường răng dính, răng sinh đôi còn có khoảng hở giữa răng dính với các răng bên cạnh. Tuy nhiên có kết quả này là vì trong 32 răng dính được nghiên cứu thì có 3 răng dính giữa một răng bình thường và một răng thừa, nên các cung răng chứa các răng này thường mất các khe hở do các răng thừa chiếm chỗ.

Trong 3 trường hợp có răng sinh đôi thì cả 3 trường hợp cung răng không có khe hở. Điều này có thể do răng sinh đôi có kích thước lớn hơn răng bình thường nên làm mất các khoảng hở của cung hàm.

\section{KẾT LUẬN}

Răng dính, răng sinh đôi là những bất thường hình dạng ít gặp (2,4\%), răng sinh đôi ít gặp hơn răng dính.

Răng dính, răng sinh đôi đều xảy ra ở vùng răng trước, hay gặp ở một bên và ở hàm dưới.

Tương quan răng hàm sữa thứ hai theo bình diện giới hạn phía xa của trẻ có răng dính, răng sinh đôi chủ yếu theo kiểu bậc xuống gần.

Tất cả trẻ có răng sinh đôi đều có cung răng thuộc loại không có khe hở. Hầu hết trẻ có răng dính đều có cung răng thuộc loại có khe hở.

\section{TÀI LIỆU THAM KHẢO}

1. Hamasha AA và Al-Khateeb T (2004). Prevalence of fused and geminated teeth in Jordanian adults. Quintessence Int, 35, 556 - 559.

2. Zengin A. Z., Celenk, P. và cộng sự (2014). Primary double teeth and their effect on permanent successors. Eur J Paediatr Dent, 15(3), 309 - 312.

3. R. R Gomes và các cộng sự (2014). Dental anomalies in primary dentition and their corresponding permanent teeth, Clinical Oral Investigations, 18(4), 1361 - 1367.

4. Cheng RB, CheX và Liu SJ et al (2003). An epidemiological survey on fusion of deciduous teeth of 4286 kindergarten children in Shenyang city. Shanghai Kou Qiang Yi Xue, 12(6), 424 - 426.

5. Hoàng Ngoc Quyết (2014). Thực trang răng sữa dính, răng sữa sinh đôi và khớp cắn ở những răng này của học sinh trường mâm non Việt Triêu, Bác sĩ Răng Hàm Măt, Đai hoc Y Hà Nôi.

6. Yeun SWH, Chan JCY và Wei SHY (1987). Double primary teeth and their relationship with the permanent successors: a radiographic study of 376 cases. Pediatric Dent, 9(1), 42 - 52.

7. Duncan WK và Helpin ML (1987). Bilateral fusion and germination: aliterature analysis and case report. Oral Surg Oral Med Oral Pathol, 64, 82 -87.

8. Gupta, Teena, Manuja và cộng sự (2015). Bilateral Fusion of Primary Mandibular İncisors: A Rare Case Report. Journal of Clinical and Diagnostic Research, 9(12), ZJ01.

9. Brook AH và Vinter GB (1970). Double teeth: $A$ retrospective study of "geminated" and "fused" teeth in children. Br Dent J, 129 (123 - 130),

\section{PHÂN TÍCH CHI PHÍ - HIÊUU QUẢ MộT Số INSULIN ANALOG SỬ DUNG TRONG ĐIỀU TRI ĐÁI THÁO ĐƯờNG TÍP 2 TẠI VIÊTT NAM DỰA TRÊNN MÔ HÌNH MARKOV}

\section{Nguyễn Minh Văn ${ }^{1}$, Kiều Thị Tuyết $M a^{2}{ }^{2}$, Nguyễn Thùy Duyên ${ }^{1}$}

\section{TÓM TẮT}

Đăt vấn đề: Đái tháo đường (ĐTĐ) típ 2 đang là một vấn đề y tế công cộng lớn trên thế giới và tại Việt Nam, với tỉ lệ mắc bệnh cao và đang có xu hướng gia tăng, ảnh hưởng nặng nề tới kinh tế và sức khỏe của người bệnh và xã hội. Insulin analog tác dụng kéo dài là một phương án điều trị ĐTĐ típ 2. Tai Việt Nam, hai insulin analog tác dụng kéo dài phổ biến nhất là insulin glargine và detemir. Mục tiêu của nghiên cứu là đánh giá chi phí - hiệu quả của hai insulin này trong

\footnotetext{
${ }^{1}$ Trường Đại học Y tế công cộng

${ }^{2}$ Trường Đại học Dược Hà Nội

Chịu trách nhiệm chính: Nguyễn Minh Văn

Email: nmv@huph.edu.vn

Ngày nhận bài: 10.5.2021

Ngày phản biện khoa học: 21.6.2021

Ngày duyệt bài: 5.7.2021
}

điều trị ĐTĐ típ 2 tại Việt Nam. Phương pháp nghiên cứu: Nghiên cửu phân tích chi phí - hiêu quả được thực hiện thông qua mô hình Markov, sử dụng các thông số đầu vào từ y văn đã được công bố trong nước và quốc tế. Mô hình Markov đánh giá trên 1000 bệnh nhân giả định, trong vòng 40 chu kỳ, với mỗi chu kỳ là 1 năm. Mô hình được xây dựng dựa trên quan điểm của xã hội. Mô hình mô phỏng chi phí và thỏa dụng dựa trên nguy cơ mắc các biến chứng ĐTÐ típ 2: hạ đường huyết, nhồi máu cơ tim, đột quy, bệnh động mạch ngoại biên, các bệnh mạch máu nhỏ hoăc tử vong. Phân tích độ nhay mồt chiều cũng đước thực hiện. Kết quả: Việc sử dụng IGlar trong điều trị ĐT̄Đ típ 2 tại Việt Nam mang lại chi phí thấp hơn (giảm VND 26.288.432.135) và thỏa dụng cao hơn (tăng 210,945 QALY) so với IDet. Phân tích độ nhay một chiêuu cho thây kết quả phân tích phụ thuộc lởn vào liêu sử dụng insulin trung bình và các thông số liên quan tới nguy cơ mắc biến chứng ĐTĐ, tuy nhiên, 